\title{
Management of insomnia and long-term use of sedative-hypnotic drugs in older patients
}

\author{
Jacqueline M. McMillan MD, Elizabeth Aitken BSc MLIS, Jayna M. Holroyd-Leduc MD
}

See also practice article by Wolkove and Baltzan on page 1517 and at www.cmaj.ca/lookup/doi/10.1503/cmaj.130260

$\mathrm{B}$ enzodiazepines and other sedativehypnotic drugs are prescribed to many older adults despite the nearly 5 -fold increased risk of adverse cognitive events associated with their use $(95 \%$ confidence interval [CI] 1.47 to 15.47$),{ }^{1,2}$ the 2.6 -fold increased risk of adverse psychomotor events (95\% CI 1.12 to 6.09), the association with falls and hip fractures $^{3,4}$ and the 5-fold increased risk of hospital admission after a motor vehicle collision. ${ }^{5}$ The number needed to treat with a sedative-hypnotic drug for improved quality of sleep is 13 , whereas the number needed to harm is $6 .{ }^{1}$ Harm can include drowsiness, fatigue, headache, nightmares and gastrointestinal disturbances. ${ }^{1}$

In the 2012 updated Beers criteria for potentially inappropriate medication use in older adults, a strong recommendation based on highquality evidence has been made to avoid all benzodiazepines in older adults. ${ }^{6}$ Yet, $16 \%-33 \%$ of older people living in the community use benzodiazepines, ${ }^{78}$ and $54 \%$ use them daily. ${ }^{9}$ The most widely reported indication is insomnia $(64 \%){ }^{7}$ People who take benzodiazepines tend to be older women, to have lower education levels, to consume less alcohol but more tobacco, to have higher depression and anxiety scores and to use other psychotropic drugs. ${ }^{2,7}$

The appropriate assessment and management of chronic insomnia is crucial. Insomnia affects quality of life and has been shown to be an independent risk factor for falls (adjusted odds ratio [OR] $1.52,95 \%$ CI 1.38 to 1.66$).{ }^{10} \mathrm{~A}$ current evidence-based consensus guideline can assist clinicians in managing chronic insomnia. ${ }^{11}$

In this review, we address questions regarding sedative-hypnotic drugs, their discontinuation and effective alternative options among older adults. This review is based on a systematic literature search (Box 1). Most of the relevant evidence identified consisted of small, short-term, randomized trials.

\section{How can long-term use of sedative- hypnotic drugs be prevented?}

Prescribing sedative-hypnotic drugs in hospital has a substantial impact on long-term use. A case-control study of new benzodiazepine prescriptions found that cases were 3 times more likely than controls to have been admitted to hospital within 30 days after the index date. ${ }^{12}$ In another study, at 1 month after discharge, patients were more likely to stop previous benzodiazepine use if they did not receive them during the hospital stay (OR 3.58, 95\% CI 1.56 to 8.21) and were more likely to start taking benzodiazepines if they were prescribed them during the hospital stay (OR 3.57, 95\% CI 1.66 to 8.08). ${ }^{13}$ No literature was identified around the role of counselling or other strategies to prevent long-term use.

\section{Are non-benzodiazepine sedative- hypnotic drugs a safer alternative?}

Medications commonly used to treat insomnia include the " $Z$ drugs" (non-benzodiazepine sedative-hypnotic drugs, of which zopiclone and zolpidem have been approved for use in
Competing interests: None declared.

Disclaimer: Jayna

Holroyd-Leduc is an

Associate Editor of CMAJ

and was not involved in the editorial decision-making process for this article.

This article has been peer reviewed.

Correspondence to: Jacqueline M. McMillan, jacqueline.mcmillan @albertahealthservices.ca

CMAJ 2013. DOI:10.1503 /cmaj.130025

\section{KEY POINTS}

- Long-term benzodiazepine use in older patients is associated with many adverse outcomes.

- Hospital admission may play a pivotal role in both the initiation and discontinuation of sedative-hypnotic drugs.

- There is a paucity of long-term safety and efficacy data for the use of non-benzodiazepine sedative-hypnotics.

- Cognitive behavioural therapy, brief behavioural interventions and benzodiazepine-tapering protocols have shown proven benefit in benzodiazepine discontinuation.

- Nonpharmacologic interventions, such as cognitive behavioural therapy and brief behavioural interventions, are of proven benefit in improving sleep parameters. 
Canada), melatonin, ramelteon, diphenhydramine, antidepressants and atypical antipsychotics. A systematic analysis of the pharmacologic treatment of insomnia in patients over 60 years old found that, although sleep was better with sedatives than with placebo, adverse cognitive events were more common (OR 4.78, 95\% CI 1.47 to 15.47), ${ }^{1}$ as were adverse psychomotor events (OR 2.25, 95\% CI 0.93 to 5.41), although the latter did not reach significance. ${ }^{1}$

\section{$Z$ drugs}

We found 2 randomized trials that compared zopiclone with triazolam in older adults ${ }^{14,15}$ (Table 1). Overall, the studies were small $(n=$ 10-41) and of short duration (15-17 days). Therefore, although the results showed improvement in some sleep-quality indices, there was insufficient evidence to support the efficacy and safety of long-term use.

Two randomized trials were found that compared zolpidem with triazolam in older adults (Table 1). ${ }^{16,17}$ Although the number of participants was greater than in the studies of zopiclone $(n=$ 205-335), the duration was short (21-28 days). As a result, the efficacy and safety of zolpidem for long-term use remains unclear. In a casecontrol study of Medicare and Medicaid data from one US state, the risk of hip fracture was increased with zolpidem use compared with no use (adjusted OR 1.95, 95\% CI 1.09 to 3.51 ) and similar compared with benzodiazepines (adjusted OR 1.47; 95\% CI 0.74 to 2.93). ${ }^{18}$ Furthermore, Health Canada has issued an advisory for zolpidem following reports of complex sleeprelated behaviours. ${ }^{19}$

Overall, trials of the $\mathrm{Z}$ drugs have shown improvement in some sleep domains. However, it is premature to presume that these drugs are

\section{Box 1: Methods}

We searched MEDLINE (1946-September 2012), Embase (1980-September 2012) and the Cochrane Database of Systematic Reviews (2005-September 2012) using the following key search terms: MeSH and Embase terms for benzodiazepines, sleep initiation and maintenance disorders, and drug withdrawal and abuse, as well as key words for sleep, addiction, dependence, insomnia, specific drug names, and terms for taper, withdrawal and alternative therapies. Further details about the literature search are available from the authors upon request. We retrieved 284 unique citations and reviewed 190 full articles. Each citation and full article was independently reviewed for inclusion by 2 of us, so that each of us reviewed two-thirds of all citations.

We included articles if the majority of patients studied were over the age of 65 years; the study was a systematic review, randomized controlled trial, cohort study or case-control study; and the focus of the study was use of benzodiazepines or comparative interventions as a sleep aid, or about their discontinuation. We excluded articles if they were not written in English; benzodiazepine use was primarily for a reason other than sleep aid; the article was a case report, case series or editorial; or only the abstract was available. either safe or effective when used long-term in older adults. Until their long-term use has been studied, these medications should be prescribed with caution to frail older adults.

\section{Melatonin}

The data for the effectiveness of melatonin as a sleep aid are mixed. In a study of melatonin versus placebo, there was lack of significant effect on sleep time, sleep latency, number of awakenings and sleep efficiency. ${ }^{20}$ However, pooled data from randomized double-blind trials of prolonged-release melatonin showed statistically significant improvement in quality of sleep $(-9.2 \mathrm{~mm}$ v. $-3.7 \mathrm{~mm}$ with placebo, as measured by the Leeds Sleep Evaluation Questionnaire visual analog scale) and decrease in subjective sleep latency ( 26 min v. 8 min with placebo; $p=0.02) .{ }^{21}$

Ramelteon, a prescription melatonin agonist, was recently approved in the United States and Japan but is not currently available in Canada. A systematic review of ramelteon found improvements in total sleep time (9 min, 95\% CI 4.94 to $12.49)$ and in latency to persistent sleep ( $-4 \mathrm{~min}$, 95\% CI -5.66 to -2.77$).{ }^{22}$ However, in subgroup analysis, there were no significant improvements among those over 65 years. ${ }^{22}$

\section{Diphenhydramine}

In a 14-day crossover trial of diphenhydramine $50 \mathrm{mg}$ versus temazepam $15 \mathrm{mg}$ versus placebo, total sleep time, sleep quality and sleep latency were not significantly improved in the diphenhydramine arm..$^{23}$ In a trial involving 14 healthy older volunteers (mean age $71.6 \mathrm{yr}$ ), psychomotor impairment was present after $75 \mathrm{mg}$ of diphenhydramine versus placebo; however, no psychomotor impairment was detected with 50-mg dose. ${ }^{24}$ The updated Beers criteria strongly advise against the use of diphenhydramine in older adults because of its anticholinergic effects. ${ }^{6}$

\section{Doxepin}

Doxepin, a histamine $\mathrm{H}_{1}$-receptor antagonist, was shown to significantly increase subjective total sleep time by 18 minutes, from 317 to 335 minutes $(p<0.01)$ after 1 week of treatment in older adults. ${ }^{25}$ In this trial, there were no reports of anticholinergic effects or memory impairment in the doxepin group. ${ }^{25}$

\section{Other agents}

We found no data on the use of atypical antipsychotics, trazodone or other antidepressants for sleep in older adults, despite the use of these medications for their sedating properties. In the general population, data supporting the use of 
trazodone for sleep in the absence of a coexisting mood disorder are lacking. ${ }^{26}$

\section{When should problematic use of sedative-hypnotics be suspected?}

In a randomized controlled discontinuation trial, patients who used more than $10 \mathrm{mg}$ of diazepam equivalent, who had high scores on a noncompliance measure or who drank more than 2 units of alcohol per day failed to achieve long-term abstinence (defined as receiving no benzodiazepine prescriptions during 15 months of follow-up). ${ }^{27}$ In a longitudinal study involving older people, long-term benzodiazepine use was associated with treatment for nervous conditions, restless sleep, being female, being divorced and having increased contact with medical services. ${ }^{7}$ Similarly, associations between benzodiazepine use and depressive or anxious symptoms, increased use of nonpsychotropic drugs and female sex were found in a study involving older benzodiazepine users in France. ${ }^{8}$
As part of the work-up for insomnia, it is necessary to investigate the reason for long-term sedative-hypnotic use and to rule out other axis I disorders such as mood and anxiety disorders. Other sleep-related disorders should also be considered, such as obstructive sleep apnea, restless leg syndrome, sleep walking and narcolepsy.

\section{What strategies are effective for stopping sedative-hypnotic drug use?}

Effective strategies, used alone or in combination, include simple recommendations to stop, tapering protocols, cognitive behavioural therapy and melatonin. In particular, there is evidence for combining tapering protocols with cognitive behavioural therapy.

Cognitive behavioural therapy is administered by registered psychologists and psychiatrists who have received special training. Sessions are usually 90 minutes long and often occur weekly over a

Table 1: Randomized controlled trials of non-benzodiazepine sedative-hypnotic drugs versus benzodiazepines for the treatment of insomnia

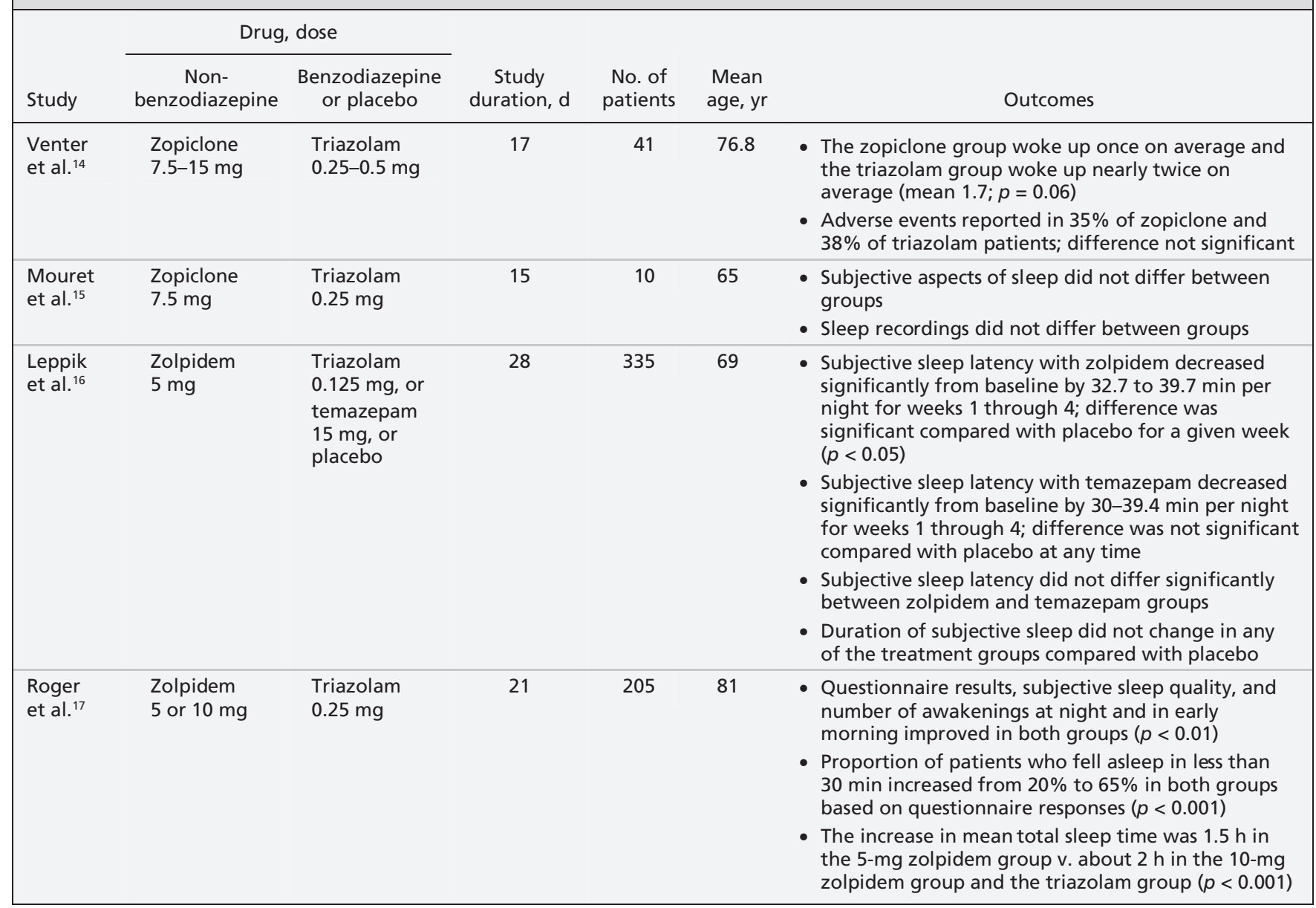


defined period. Treatments consist of behavioural, cognitive and educational interventions that target different aspects of insomnia. ${ }^{28}$ Interventions include sleep restriction (limiting time in bed to actual sleep time), stimulus control (re-associating the bedroom with sleep) and cognitive therapy designed to change faulty beliefs about sleep. ${ }^{28}$

In a cohort study involving 31 patients taking benzodiazepines or a $\mathrm{Z}$ drug who received a recommendation to alter their sedative drug use, $68 \%$ were adherent at follow-up. ${ }^{29}$ In a trial involving 591 patients, those in the intervention group were given instructions to withdraw, reduce or change psychotropic medications, in addition to a 1-hour lecture about the drugs and their adverse effects. The number of patients who were regular users of benzodiazepines decreased by $35 \%$ in the intervention group and increased by $4 \%$ in the controls. ${ }^{30}$

Among patients with insomnia who had been using hypnotic-sedative drugs for at least 1 month, cognitive behavioural therapy resulted in significant reductions in Pittsburgh Sleep Quality Index scores from 13 at baseline to 3 at 3-month followup to 2 at 6-month follow-up (lower scores indicate reduced severity of sleep disturbance); reductions in sleep latency from 60 minutes at baseline to 28 minutes at 3-month follow-up to 30 minutes at 6-month follow-up; and improvement in sleep efficiency score (representing the percentage of time in bed spent asleep) improved from 2.2 at baseline to 0.7 at both the 3- and 6-month followup assessments (Table 2). ${ }^{31}$ Patients who received

Table 2: Results of randomized controlled trials of the effect of cognitive behavioural therapy on sleep quality

\begin{tabular}{|c|c|c|c|c|c|c|}
\hline \multirow[b]{2}{*}{ Study } & \multirow{2}{*}{$\begin{array}{c}\text { Duration of } \\
\text { treatment }\end{array}$} & \multirow[b]{2}{*}{ Participants } & \multirow{2}{*}{$\begin{array}{l}\text { Mean } \\
\text { age, yr }\end{array}$} & \multicolumn{2}{|c|}{ Study group } & \multirow[b]{2}{*}{ Outcomes } \\
\hline & & & & Intervention & Comparator & \\
\hline \multirow[t]{2}{*}{$\begin{array}{l}\text { Morgan } \\
\text { et al. } .^{31}\end{array}$} & \multirow[t]{2}{*}{$\begin{array}{l}6 \text { wk of } \\
\text { active } \\
\text { treatment; } \\
\text { follow-up } \\
\text { at } 3 \text { and } \\
6 \text { mo }\end{array}$} & \multirow[t]{2}{*}{$\begin{array}{l}209 \text { people using } \\
\text { benzodiazepines } \\
\text { for }>1 \mathrm{mo} \text {; mean } \\
\text { duration of use } \\
13.4 \mathrm{yr}\end{array}$} & \multirow[t]{2}{*}{68} & \multirow[t]{2}{*}{$\begin{array}{l}\text { Six } 50-\text { min } \\
\text { sessions of } \\
\text { cognitive } \\
\text { behavioural } \\
\text { therapy }\end{array}$} & \multirow[t]{2}{*}{$\begin{array}{l}\text { Usual care } \\
\text { with crossover } \\
\text { to cognitive } \\
\text { behavioural } \\
\text { therapy }\end{array}$} & $\begin{array}{l}\text { At } 3 \text { mo, intervention group had significant } \\
\text { improvement in Pittsburgh scores (mean } \\
\text { difference }-3.8,95 \% \mathrm{Cl}-4.8 \text { to }-2.8 \text { ), decrease } \\
\text { in sleep latency (mean difference }-24.1,95 \% \mathrm{Cl} \\
-37.2 \text { to }-11.1 \text { ), improvement in sleep efficiency } \\
\text { (mean difference }-0.9,95 \% \mathrm{Cl} 1.2 \text { to }-0.6 \text { ) and } \\
\text { increase in total sleep time (mean difference } \\
0.5 \text { min, } 95 \% \mathrm{Cl} 0.1 \text { to } 0.8 \text { ); } 47.4 \% \mathrm{v} .17 .3 \% \\
\text { reported low-frequency use ( } p<0.001 \text { ); } 30 \% \mathrm{v} \text {. } \\
11 \% \text { reported zero hypnotic drug use over } 7 \text {-d } \\
\text { follow-up assessment period ( } p=0.005 \text { ) }\end{array}$ \\
\hline & & & & & & $\begin{array}{l}\text { At } 6 \text { mo, intervention group had significant } \\
\text { decrease in sleep latency (mean difference } \\
-27.9 \text { min }(95 \% \mathrm{Cl}-43.4 \text { to }-12.6) \text { and } \\
\text { improvement in sleep efficiency score (mean } \\
\text { difference }-1(95 \% \mathrm{Cl}-1.3 \text { to }-0.6) ; 54 \% \mathrm{v} .18 \% \\
\text { reported low-frequency use }(p<0.001) ; 33 \% \mathrm{v} \text {. } \\
8 \% \text { reported zero hypnotic drug use }(p<0.001)\end{array}$ \\
\hline $\begin{array}{l}\text { Morin } \\
\text { et al. }{ }^{32}\end{array}$ & $10 w k$ & $\begin{array}{l}76 \text { chronic } \\
\text { benzodiazepine } \\
\text { users ( }>50 \% \text { of } \\
\text { nights for }>3 \mathrm{mo}) \text {; } \\
\text { mean } 6.7 \text { nights } \\
\text { per wk; mean } \\
\text { duration of use } \\
19.3 \mathrm{yr}\end{array}$ & 62.5 & $\begin{array}{l}\text { Combined } \\
\text { benzodiazepine } \\
\text { tapering and } \\
\text { cognitive } \\
\text { behavioural } \\
\text { therapy }\end{array}$ & $\begin{array}{l}\text { Benzodiazepine } \\
\text { tapering alone } \\
\text { or cognitive } \\
\text { behavioural } \\
\text { therapy alone }\end{array}$ & $\begin{array}{l}\text { Overall, } 90 \% \text { reduction in quantity of } \\
\text { benzodiazepine consumption and } 80 \% \\
\text { reduction in frequency of medicated nights } \\
\text { across the } 3 \text { groups; } 63 \% \text { of patients were } \\
\text { benzodiazepine free within } 7 \text { wk on average; } \\
85 \% \text { in combined treatment arm were } \\
\text { benzodiazepine free after initial intervention } \\
\text { v. } 48 \% \text { in tapering arm and } 54 \% \text { in cognitive } \\
\text { behavioural therapy arm }\end{array}$ \\
\hline $\begin{array}{l}\text { Baillargeon } \\
\text { et al. }{ }^{33}\end{array}$ & $8 w k$ & $\begin{array}{l}65 \text { daily } \\
\text { benzodiazepine } \\
\text { users for }>3 \mathrm{mo} \text {; } \\
\text { mean duration } \\
\text { of use } 152 \mathrm{mo} \\
(12.7 \mathrm{yr} \text { ) }\end{array}$ & 67.4 & $\begin{array}{l}\text { Combined } \\
\text { benzodiazepine } \\
\text { tapering and } \\
\text { cognitive } \\
\text { behavioural } \\
\text { therapy ( } 90-\mathrm{min} \\
\text { group session } \\
\text { weekly for } 8 \mathrm{wk} \text { ) }\end{array}$ & $\begin{array}{l}\text { Benzodiazepine } \\
\text { tapering alone }\end{array}$ & $\begin{array}{l}77 \% \text { in combined treatment arm v. } 38 \% \text { in } \\
\text { tapering arm were benzodiazepine free } \\
\text { immediately after treatment (OR } 5.3,95 \% \mathrm{Cl} \\
1.8 \text { to } 16.2 \text { ); this outcome persisted at } 12 \mathrm{mo} \text {, } \\
\text { with } 70 \% \text { benzodiazepine free in combined } \\
\text { treatment arm v. } 24 \% \text { in tapering only arm } \\
\text { (OR } 7.2,95 \% \mathrm{Cl} 2.4 \text { to } 23.7 \text { ) }\end{array}$ \\
\hline $\begin{array}{l}\text { Voshaar } \\
\text { et al. }{ }^{34}\end{array}$ & $3 \mathrm{mo}$ & $\begin{array}{l}180 \text { regular } \\
\text { benzodiazepine } \\
\text { users for }>3 \mathrm{mo} \text {; } \\
\text { mean duration } \\
\text { of use } 165 \mathrm{mo} \\
(13.8 \mathrm{yr})\end{array}$ & 63.4 & $\begin{array}{l}\text { Benzodiazepine } \\
\text { tapering alone or } \\
\text { combined with } \\
\text { cognitive } \\
\text { behavioural } \\
\text { therapy ( } 2 \text {-h session } \\
\text { weekly for } 5 \mathrm{wk} \text { ) }\end{array}$ & Usual care & $\begin{array}{l}62 \% \text { in tapering arm and } 58 \% \text { in combined } \\
\text { treatment arm were successful with } \\
\text { discontinuation v. } 21 \% \text { in usual care arm }\end{array}$ \\
\hline
\end{tabular}


cognitive behavioural therapy reported reductions in hypnotic drug use (54\% reported low-frequency use v. $18 \%$ of controls; $33 \%$ in the intervention group v. $8 \%$ of controls reported zero hypnotic drug use). ${ }^{31}$

Cognitive behavioural therapy in combination with a drug tapering program may result in greater success. In a randomized trial, the frequency of medicated nights was lower and the proportion of benzodiazepine-free patients higher in the combined treatment group than in the groups that received cognitive behavioural therapy only or tapering alone (Table 2). ${ }^{32}$ There was a $90 \%$ overall reduction in the quantity of benzodiazepines used and an $80 \%$ overall reduction in the frequency of medicated nights across all 3 treatment groups, which was maintained at 3 and 12 months' follow-up..$^{32}$ In a similar trial, a greater proportion of participants in the combined treatment group than in the tapering only group reported completed discontinuation of hypnotic drugs (Table 2). ${ }^{33}$ At the 12-month follow-up, $70 \%$ in the combined treatment group, as compared with $24 \%$ in the tapering only group, were benzodiazepine free..$^{33}$ Patients took an average of 7 weeks to stop benzodiazepine use..$^{32}$

In a trial involving 180 long-term benzodiazepine users randomly assigned to tapering plus cognitive behavioural therapy, tapering alone or usual care, discontinuation of benzodiazepine use was significantly more successful in both intervention groups than in the usual care group, with no significant difference between the intervention groups (Table 2). ${ }^{34}$ Patients who were using a benzodiazepine other than diazepam were switched to an equivalent dose of diazepam for 2 weeks. If more than one benzodiazepine was being used, the dosages were added together. The daily equivalent dose of diazepam was reduced by $25 \%$ per week over 4 weekly visits. Overall, $88 \%$ of the physicians found the protocol to be feasible in practice, $83 \%$ said they would encourage others to use it, and $52 \%$ had already started using it for other patients. ${ }^{34}$

In a randomized trial of a benzodiazepine withdrawal program involving 180 patients, the independent predictors of successful benzodiazepine discontinuation were offering a tapering program (hazard ratio [HR] 2.9, 95\% CI 1.8 to 4.8 ), combining a tapering program with cognitive behavioural group therapy (HR 2.4, 95\% CI 1.5 to 3.9 ), a lower daily benzodiazepine dose at the start (HR 1.5, 95\% CI 1.2 to 1.9), a substantial dosage reduction by patients themselves before the tapering protocol (HR 2.1, 95\% CI 1.4 to 3.3 ), less severe benzodiazepine dependence (HR 2.4, 95\% CI 1.1 to 5.2), and no concomitant alcohol use (HR 1.7, 95\% CI 1.2 to 2.5 ). ${ }^{27}$
In a placebo-controlled trial involving 38 long-term benzodiazepine users asked by their general practitioner to participate in a discontinuation program in combination with melatonin or placebo, there was no significant difference in outcomes between the groups. ${ }^{35}$ However, among older patients who were encouraged to decrease their benzodiazepine doses while taking melatonin or placebo, sleep quality scores, as measured by the Northside Hospital Sleep Medicine Institute Test, were improved in the melatonin group, and 9 of 14 habitual benzodiazepine users were able to discontinue benzodiazepine use. ${ }^{36}$

\section{Are nonpharmacologic therapies effective for insomnia?}

Nonpharmacologic therapies have been successful to varying degrees in older adults with insomnia. Among the most successful strategies are cognitive behavioural therapy and brief behavioural therapy.

In a 6-week study involving 46 adults with chronic primary insomnia assigned to cognitive behavioural therapy, zopiclone $7.5 \mathrm{mg}$ or placebo, the total wake time at 6 weeks was reduced by $52 \%$ in the cognitive behavioural therapy group (from $108 \mathrm{~min}$ to $51 \mathrm{~min}$ ), as compared with $4 \%$ in the zopiclone group (from $103 \mathrm{~min}$ to $99 \mathrm{~min}$ ) and $16 \%$ in the placebo group (from $154 \mathrm{~min}$ to $130 \mathrm{~min}$ ). ${ }^{28}$ At the 6month follow-up, total sleep time continued to increase in the cognitive behavioural therapy group only (by 26 minutes [from 336 min at 6 wk to $362 \mathrm{~min}$ at $6 \mathrm{mo}$ ]), total wake time decreased further (from $52 \mathrm{~min}$ at $6 \mathrm{wk}$ to 47 min at $6 \mathrm{mo}$ ), sleep efficiency improved (from $81 \%$ at 6 wk to $83 \%$ at $6 \mathrm{mo}$ ), and slow-wave sleep increased (from $80 \mathrm{~min}$ at $6 \mathrm{wk}$ to $84 \mathrm{~min}$ utes at $6 \mathrm{mo}){ }^{28}$

Cognitive behavioural therapy can be time intensive and requires a specially trained psychologist or psychiatrist. Brief behavioural interventions have been explored as an alternative, which consist of individualized 45-60-minute sessions followed by a 30 -minute follow-up session and two 25-minute telephone calls. The intervention involves reducing time spent in bed not sleeping; getting up at the same time every day; not going to bed unless tired; and not staying in bed unless asleep. Napping is discouraged. In a randomized trial involving 79 older adults with chronic insomnia, brief behavioural therapy resulted in significantly better outcomes for depression and anxiety ratings, sleep quality index, sleepiness scale and insomnia remission compared with only providing information. ${ }^{37}$ In 
the intervention group, $55 \%$ of the participants no longer met the criteria for insomnia at the end of treatment, as compared with $13 \%$ in the information-only group. ${ }^{37}$ At the 6-month follow-up, $64 \%$ no longer met the criteria for insomnia, and the mean total sleep time had significantly increased further, from 340 minutes to 386 minutes. ${ }^{37} \mathrm{~A}$ similar randomized trial of brief behavioural therapy resulted in remission rates of $53 \%$ at follow-up..$^{38}$

Exercise may play a role in the treatment of insomnia. In randomized controlled trials, participants who took tai chi 2-3 times per week for 3-6 months had significant reductions in Pittsburgh Sleep Quality Index scores compared with controls, ${ }^{39,40}$ from 9.4 before the intervention to 3.6 afterward (where a lower score indicates less severe sleep symptoms). ${ }^{39}$

Sleep education of caregivers may help improve sleep among patients with dementia. The intervention consists of 4 sessions in which caregivers are taught nonpharmacologic strategies to improve sleep, common causes of sleep problems in dementia and common causes for nighttime awakenings and are given assistance in developing sleep plans. A trial of sleep education resulted in significant reductions in caregiver ratings of resident wandering, inappropriate behaviours at night and in excessive daytime napping. ${ }^{41}$

\section{Unanswered questions}

The use of benzodiazepines and other sedativehypnotic drugs in older adults is frequent and associated with adverse outcomes. Given the paucity of safety and efficacy data supporting the long-term use of non-benzodiazepine sedativehypnotic agents, should use of these medications be approached by clinicians as a problem to be managed, similar to benzodiazepine use? Furthermore, despite evidence for the efficacy of cognitive behavioural therapy and brief behavioural therapy for the management of chronic insomnia and benzodiazepine discontinuation, these modalities are not readily available to patients. The question remains regarding how best to translate this evidence into practice.

\section{References}

1. Glass J, Lanctôt KL, Herrmann N, et al. Sedative hypnotics in older people with insomnia: meta-analysis of risks and benefits. BMJ 2005;331:1169.

2. Paterniti S, Dufouil C, Alpérovitch A. Long-term benzodiazepine use and cognitive decline in the elderly: the epidemiology of vascular aging study. J Clin Psychopharmacol 2002;22: 285-93.

3. Allain H, Bentué-Ferrer D, Polard E, et al. Postural instability and consequent falls and hip fractures associated with use of hypnotics in the elderly. Drugs Aging 2005;22:749-65.

4. Ryynänen OP, Kivelä SL, Honkanen R, et al. Medications and chronic diseases as risk factors for falling injuries in the elderly. Scand J Soc Med 1993;21:264-71.
5. Meuleners LB, Duke J, Lee AH, et al. Psychoactive medications and crash involvement requiring hospitalization for older drivers: a population-based study. J Am Geriatr Soc 2011;59:1575-80.

6. American Geriatrics Society updated Beers criteria for potentially inappropriate medication use in older adults. J Am Geriatr Soc 2012;60:616-31

7. Jorm AF, Grayson D, Creasey H, et al. Long-term benzodiazepine use by elderly people living in the community. Aust $N Z$ J Public Health 2000;24:7-10.

8. Lechevellier-Michel N, Berr C, Fourrier-Réglat A. Incidence and characteristics of benzodiazepine use in an elderly cohort: the EVA study. Therapie 2005;60:561-6.

9. Simon GE, Ludman EJ. Outcome of new benzodiazepine prescriptions to older adults in primary care. Gen Hosp Psychiatry 2006;28:374-8

10. Avidan AY, Fries BE, James ML. Insomnia and hypnotic use, recorded in the minimum data set, as predictors of falls and hip fractures in Michigan nursing homes. J Am Geriatr Soc 2005;53: 955-62.

11. Schutte-Rodin S, Broch L, Buysse D. Clinical guideline for the evaluation and management of chronic insomnia in adults. J Clin Sleep Med 2008;4:487-504.

12. Grad R, Tamblyn R, Holbrook AM, et al. Risk of new benzodiazepine prescription in relation to recent hospitalization. $J \mathrm{Am}$ Geriatr Soc 1999;47:184-8.

13. Zisberg A, Shadmi E, Sinoff G, et al. Hospitalization as a turning point for sleep medication use in older adults. Drugs Aging 2012;29:565-76.

14. Venter CP, Joubert PH, Stahmer SD, et al. Zopiclone compared with triazolam in insomnia in geriatric patients. Curr Therapeutic Res 1986;40:1062-8.

15. Mouret J, Ruel D, Maillard F, et al. Zopiclone versus triazolam in insomniac geriatric patients: a specific increase in delta sleep with zopiclone. Int Clic Psychopharmacol 1990;(Suppl 2):47-55

16. Leppik IE, Roth-Schechter B, Gray GW, et al. Double-blind, placebo-controlled comparison of zolpidem, triazolam and temazepam in elderly patients with insomnia. Drug Dev Res 1997; 40:230-8.

17. Roger M, Attali P, Coquelin JP. Multicenter, double-blind, controlled comparison of zolpidem and triazolam in elderly patients with insomnia. Clin Ther 1993;15:127-36.

18. Wang PS, Bohn RL, Glynn RJ, et al. Zolpidem use and hip fractures in older people. J Am Geriatr Soc 2001;49:1685-90.

19. Recalls and alerts: Sublinox (zolpidem tartrate) — association with complex sleep behaviours - for health professionals. Ottawa (ON): Health Canada; 2011. Available: www.healthycanadians .gc.ca/recall-alert-rappel-avis/hc-sc/2011/14663a-eng.php (accessed 2013 July 26).

20. Baskett JJ, Broad JB, Wood PC, et al. Does melatonin improve sleep in older people? A randomised crossover trial. Age Ageing 2003;32:164-70.

21. Lemoine P, Wade AG, Katz A, et al. Efficacy and safety of prolonged-release melatonin for insomnia in middle-aged and elderly patients with hypertension: a combined analysis of controlled trials. Integr Blood Press Control 2012;5:9-17.

22. Liu J, Wang LN. Ramelteon in the treatment of chronic insomnia: systematic review and meta-analysis. Int J Clin Pract 2012; 66:867-73

23. Glass JR, Sproule BA, Herrmann N, et al. Effects of 2-week treatment with temazepam and diphenhydramine in elderly insomniacs. J Clin Psychopharmacol 2008;28:182-8.

24. Glass JR, Sproule BA, Herrmann N, et al. Acute pharmacological effects of temazepam, diphenhydramine, and valerian in healthy elderly subjects. J Clin Psychopharmacol 2003;23:260-8.

25. Lankford A, Rogowski R, Essink B, et al. Efficacy and safety of doxepin $6 \mathrm{mg}$ in a four-week outpatient trial of elderly adults with chronic primary insomnia. Sleep Med 2012;13:133-8.

26. James SP, Mendelson WB. The use of trazodone as a hypnotic: a critical review. J Clin Psychiatry 2004;65:752-5.

27. Voshaar RCO, Gorgels WJ, Mol AJ, et al. Predictors of long-term benzodiazepine abstinence in participants of a randomized controlled benzodiazepine withdrawal program. Can J Psychiatry 2006;51:445-52.

28. Sivertsen B, Omvik S, Pallesen S, et al. Cognitive behavioral therapy vs zopiclone for treatment of chronic primary insomnia in older adults. JAMA 2006;295:2851-8.

29. Joester J, Vogler CM, Chang K, et al. Hypnosedative use and predictors of successful withdrawal in new patients attending a falls clinic: a retrospective cohort study. Drugs Aging 2010;27: 915-24.

30. Salonoja M, Salminen M, Aarnio P, et al. One-time counselling decreases the use of benzodiazepines and related drugs among community-dwelling older persons. Age Ageing 2010; 39:313-9. 
31. Morgan K, Dixon S, Mathers N, et al. Psychological treatment for insomnia in management of longterm hypnotic drug use: a pragmatic randomized controlled trial. Br J Gen Pract 2003;53:923-8.

32. Morin CM, Bastien C, Guay B, et al. Randomized clinical trial of supervised tapering and cognitive behavior therapy to facilitate benzodiazepine discontinuation in older adults with chronic insomnia. Am J Psychiatry 2004;161:332-42.

33. Baillargeon L, Landreville P, Verreault R, et al. Discontinuation of benzodiazepines among older adults treated with cognitive-behavioral therapy combined with gradual tapering: a randomized trial. CMAJ 2003;169:1015-20.

34. Voshaar RCO, Gorgels WJ, Mol AJ, et al. Tapering off long-term benzodiazepine use with or without group cognitive-behavioral therapy: three-condition, randomized controlled trial. Br J Psychiatry 2003; 182:498-504.

35. Vissers FH, Knipschild PG, Crebolder HF. Is melatonin helpful in stopping the long-term use of hypnotics? A discontinuation trial. Pharm World Sci 2007;29:641-6.

36. Garzón C, Guerrero JM, Aramburu O, et al. Effect of melatonin administration on sleep, behavioral disorders and hypnotic drug discontinuation in the elderly: a randomized, double-blind, placebo-controlled study. Aging Clin Exp Res 2009;21:38-42.

37. Buysse DJ, Germain A, Moul DE, et al. Efficacy of brief behavioral treatment for chronic insomnia in older adults. Arch Intern Med 2011;171:887-95.

38. Germain A, Moul DE, Franzen PL, et al. Effects of brief behavioral treatment for late-life insomnia: preliminary findings. J Clin Sleep Med 2006;2:403-6.

39. Nguyen $\mathrm{MH}$, Kruse A. A randomized controlled trial of tai chi for balance, sleep quality and cognitive performance in elderly Vietnamese. Clin Interv Aging 2012;7:185-90.

40. Chen MC, Liu HE, Huang HY. The effect of a simple traditional exercise programme (Baduanjin exercise) on sleep quality of older adults: a randomized controlled-trial. Int J Nurs Stud 2012;49:265-73.

41. McCurry SM, LaFazia DM, Pike KC, et al. Development and evaluation of a sleep education program for older adults with dementia living in adult family homes. Am J Geriatr Psychiatry 2012;20:494-504.

Affiliations: Department of Internal Medicine (McMillan), Foothills Hospital; Knowledge Management Department (Aitken), Alberta Health Services; Section of Geriatrics, Departments of Medicine and Community Health Sciences (Holroyd-Leduc), University of Calgary; and Seniors Health Strategic Clinical Network (Holroyd-Leduc), Alberta Health Services, Calgary, Alta.

Contributors: All of the authors contributed to the conception and design of the article. Jacqueline McMillan drafted the manuscript and Elizabeth Aitken and Jayna Holroyd-Leduc critically revised it. All of the authors approved the final version submitted for publication.

\section{How you can get involved in the CMA!}

The CMA is committed to providing leadership for physicians and promoting the highest standard of health and health care for Canadians. To strengthen the association and be truly representative of all Canadian physicians the CMA needs to hear from members interested in serving in elected positions and on appointed committees and advisory groups. The CMA structure comprises both governing bodies and advisory bodies either elected by General Council or appointed by the CMA Board of Directors. The Board of Directors elected by General Council - has provincial/territorial, resident and student representation, is responsible for the overall operation of the CMA and reports to General Council on issues of governance.

CMA committees advise the Board of Directors and make recommendations on specific issues of concern to physicians and the public. Five core committees mainly consist of regional, resident and student representation while other statutory and special committees and task forces consist of individuals with interest and expertise in subject-specific fields. Positions on one or more of these committees may become available in the coming year.

For further information on how you can get involved please go to http://www .cma.ca/membercentre/how-you-can-get-involved, or contact

Cherise Araujo, Corporate and Governance Services Canadian Medical Association

1867 Alta Vista Drive, Ottawa ON K1G 5 W8

Fax 613 526-7570, Tel $800663-7336$ x1949 cherise.araujo@cma.ca

By getting involved, you will have an opportunity to make a difference. We hope to hear from you!

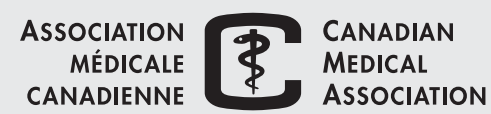

